\title{
Head Teachers' Beliefs and Practices about Teaching and Learning in Pakistani Public Schools
}

\author{
Asif Khan \\ Department of Educational Development, Karakoram International University, Gilgit, Pakistan \\ Email: asif.khan@kiu.edu.pk
}

Received 28 October 2015; accepted 19 December 2015; published 22 December 2015

Copyright (C) 2015 by author and Scientific Research Publishing Inc.

This work is licensed under the Creative Commons Attribution International License (CC BY). http://creativecommons.org/licenses/by/4.0/

cC) (i) Open Access

\begin{abstract}
Very limited research focusing on instructional contribution of Pakistani public school administrators has emerged from the educational landscape of Pakistan. Therefore, the present study highlights some of the core issues related to the instructional contribution of two head teachers situated in public schools. While focusing on instruction-related practices, the two case studies particularly examine the head teachers' engagements in supervisory processes and in-school capacity development initiatives. The study notes that despite the presence of required human and physical resources, the two head teachers make limited contributions towards the instructional quality of their respective schools. A vague understanding about their roles, a limited capacity building opportunities, and an absence of an accountability mechanism prevent the two head teachers from becoming more involved in the said processes. The study maintains that a new organizational culture needs to be introduced that re-conceptualizes the role of Pakistani head teachers while emphasizing the above-mentioned factors.
\end{abstract}

\section{Keywords}

Public Schools, Head Teachers, Supervisory Roles, In-School Capacity Building Opportunities

\section{Introduction}

In the context of developing countries, it has been acknowledged that the academic performance of students is contingent upon multiple in-school factors such as the availability of instructional material, the number of qualified teachers, and the quality of the school administration (Harber \& Davies, 1997; Fuller, 1987; Plank, 1987). Except for the school administration, a plethora of empirical studies focusing on the aforementioned factors has 
emerged from developing countries including Pakistan. As a result, several aspects of school administration, especially those related to teaching and learning, are still undiscovered from the educational landscape of Pakistan (Khan, 2012). Additionally, researchers have identified numerous gaps that minimize the vitality of principals in Pakistani schools, such as inadequate induction, preparation, and selection processes of head teachers (Khan, 2004) as well as the head teachers' vague understanding about the concept of leadership and limited supervisory role (Warwick \& Reimers, 1995). Under these circumstances, one can assume that the contribution of head teachers towards the instructional development of their schools is minimal.

Today, both in the developed and developing countries, educational reforms have prioritized the process of leadership development (Wallace Foundation, 2012; Bush, 2009). These reforms have conceived a new role of school administrators capable of understanding the administrative, educational, and the social functions (of headship) with special emphasis on the instructional development of schools. School administrators are expected to understand and practice the ethos of instructional leaders while focusing on such academic tasks as developing curriculum, visiting classes, arranging in-professional development programs, providing feedback, using test results as a tool for making important instructional decisions, monitoring lesson planning, demonstrating modeling, and providing instruction-related resources (Pansiri, 2008; McEwan, 2003; Jenkins, 2009a, 2009b; Blase \& Blase, 1999; Fink \& Resnick 1999; Krug, 1992). However, in Pakistan, educational reforms are not explicit enough to conceive instruction-oriented leaders for the schools, which cater to the educational needs of 75 percent of the total population. For instance, the last National Educational Policy (Ministry of Education, 2009) only uses three sentences to elaborate the importance of school administrators:

"In contrast, most persons at management positions in Pakistan's education sector have no training in the function. Head teachers... are mostly appointed from amongst the teacher cadre (college or school), without much management experience... A management cadre for education, with specified training and qualification requirements, shall be introduced” (pp. 28-29).

The Educational Policy does not describe what kinds of training should be provided to the school heads or what kinds of administrators the schools need in Pakistan. In the context of Western developed countries, the emergence of principals as educational leaders resulted from a plethora of research that Anglo-American scholars conducted during the last decade (Oplatka, 2004). The absence or limitation of such literature in the Pakistani context provides some justification for not developing a coherent and clear policy about Pakistani school administrators. Additionally, it may be difficult to determine what aspect (induction, selection, development) of school administration needs to be addressed on a priority basis. Therefore, the present study is an attempt to highlight some of the core issues related to the contribution of head teachers in the educational development of Pakistani public schools. Additionally, the research can be helpful to determine what needs to be done regarding the redefinition of the roles of Pakistani head teachers.

\section{Objectives of the Study}

Schools, whether situated in developed or developing countries, primarily expect their administrators to play the role of principals capable of addressing the instructional development of their schools (Waters \& Marzano, 2006; Memon \& Bana, 2005). Therefore, the present study was conducted to examine the instruction-related practices of two head teachers situated in two government secondary schools. While analyzing the instruction-related practices, the study particularly examines the head teachers' engagements in supervisory processes and inschool capacity development initiatives.

\section{Methodology}

Due to three reasons, this study used the qualitative approaches to generate data. Firstly, very limited qualitative research has emerged from Pakistan that can be used effectively for evidence-based policy-making (USAID, 2006). Secondly, since "the "thick descriptions necessary for understanding the complex nature of leadership in terms of its effect on teachers and the sociocultural context of the school are noticeably lacking” (Blasé, 1987: p. 595), the study opted for qualitative approaches. Thirdly, due to the exploratory (Ogawa \& Malen, 1991) and contemporary nature of the topic, the study used the Case Study method. According to Stake (1995), "A case study is an empirical inquiry that investigates a contemporary phenomenon within its real-life context” (p. 13). Some of the tools used to accumulate the data included formal and informal interviews, document reviews, and 
observations. I developed two separate interview protocols each for school teachers and head teachers. I developed a total of 12 questions for head teachers and 10 questions for teachers which was focusing on head teachers supervisory role (visiting class rooms; providing feedback etc.) and their involvement in in-school professional development programs. The duration of each interview was 45 - 60 minutes which was recorded and transcribed for thematic analysis. The researcher personally conducted interviews in two schools. Since the approach was case study which also allows the researchers to take an event or instance to explore a phenomenon (Stark \& Torrance, 2005), I preferred to select only two school heads and four teachers (two from each school) through a convenience sampling strategy to generate data for this study. The head teachers of both schools have more than two decades of teaching experience and almost five years of administrative experience at the primary, middle, and high school levels. The head teacher of GSA, who has an M.Ed. degree, has expertise in the teaching of Urdu (the national language of Pakistan), Islamic Studies, and Arabic subjects, whereas the head teacher of GSB, who has a B.Ed. degree, has expertise in the teaching of mathematics, English, and social studies. The head teacher of GSA received numerous training opportunities related to teaching and learning; however, he only attended a three-day workshop on school administration. Not only did the head teacher of GSB attend several training sessions about AV aids, teaching methodologies, school improvement plan, and utilization of instructional resources, but also he attended many relevant workshops, such as Certificate in Educational Leadership and Management (CELM) that covered various dimensions of school education and management. Likewise, the four teachers had B.Ed. degrees and more than ten years of teaching experiences in government schools.

\section{Literature Review}

Both developed and developing countries acknowledge how the effectiveness of school administrators affects the overall academic performance of students (Bush, 2008; Waters \& Marzano, 2006). However, school heads in developing countries, including Pakistan, often have a limited contributory role in terms of teaching and learning. Researchers have attributed the passivity of school administrators of developing countries to the schools' organizational culture (Oplatka, 2004; Rizvi, 2008; Simkin et al. 1998). For instance, it has been reported that Pakistan and other developing countries select the school administrators from the teaching staff based on the length of teaching experiences (Kandasamay \& Blaton, 2004; Harber \& Davies, 1997). Prior to their appointment, administrators received neither job-related training nor orientation; it is assumed that their protracted teaching experience is enough to make them efficient school administrators. In Pakistan, almost 200,000 school administrators only have qualifications that make them eligible for teaching positions, such as a Primary Teaching Certificate, Certificate of Teaching, and Bachelor of Education (Khan, 2004). However, “... school leadership is a different role from teaching and requires separate and specialized preparation” (Westhuizen \& Vuuren, 2007 as cited in Bush, 2005: p.125). Researchers have already expressed their dissatisfaction about the productivity of the aforementioned teachers' preparation programs in Pakistan (Mohammad \& Jones, 2008; USAID, 2006; UNESCO, 2003; Kizilbash, 1998; Hoodbhoy, 1998).

According to Simkin et al. (1998), due to the dearth of required knowledge and skills, school administrators are less motivated to bring change in their schools. Warwick \& Reimers (1995) stated the following about the Pakistani school administrators: "With no clear definition of who they are and what they are supposed to do, school heads are adrift in the educational system (...) they were not trained to be leaders, did not see themselves as leaders, and did not act like leaders" (p. 101). They added, "They rarely supervise other teachers, help them to develop greater self-confidence and better teaching skills, or work with them in other ways...” (p. 99). Harber \& Davies (1997) asserted that instructional development is an essential feature of school leaders, but in a centralized educational system of developing countries school administrators have a limited role regarding the development of certain aspects of instruction. Oplatka (2004) attributed the limited instructional role of administrators to the absence of proper capacity building opportunities, which lead them to become more administrativeoriented. Khaki (2005) asserted that in Pakistani schools, "Heads are seen as administrators rather than teachers or educators; they have neither the skills nor the time to engage in teaching or coaching” (p. 35). Memon, Ali, Simkin, \& Garrett (2000) stated that administrators in Pakistani schools have very limited understanding and control about curriculum development and enrichment. They assume that since the government is responsible for the development of curriculum, they can neither modify nor add additional material while teaching a particular topic (Khan, 2010).

In the centralized education system of Pakistan, more than seventy percent of the school-going children are 
dependent on the public school system. Research suggests that the centralized system is another factor that limits the administrative freedom and efficiency of school administrators. In the context of developing countries, Douglas (1998) pointed out that the "upward looking" tendencies of administrators prevent the administrators from taking the initiative. He added that one of the implications of this "upward looking" attitude is that people do not become loyal to their organizations; instead, they are more loyal to their bosses. "The concepts of innovations and efficiency remain alien terms when school heads become a tool of implementing policies coming from the higher echelon” (Khan, 2010). According to Simkin et al. (1998), another drawback of this system is that school heads give more importance to rules, regulations, and obedience rather than innovation and change. Kandasamay \& Blaton (2004) pointed out that because of this top down culture, the professional freedom of heads is compromised on certain matters, such as the hiring and firing of teachers, control of financial matters, etc.

Harber \& Davies (1997) pointed out that the centralized educational system of developing countries prevents the administrators from using their powers in a democratic manner; instead, authoritarianism is more evident in their practices. One of the results of this behavior of principals is that it obstructs the nurturing of a collegial culture in school; principals are "likely to refrain from involving teachers and parents in decision-making, participative leadership, delegation of responsibilities, or major school change initiations” (Oplatka, 2004: p. 440). Rizvi (2008) asserted that school administrators in Pakistan, who are the product of the Top Down Organizational Model, do not want to surrender their traditional power and authority: this reluctance to change makes them become more administrative-oriented. The administrative tendencies lead them to get involved in such activities as maintenance of records, class scheduling, and the provision of instructional material (Plank, 1987).

\section{Findings}

Both government schools A and B (GSA and GSB) offer free education for boys from grades one through ten. Both schools have a typical student/teacher ratio; the total number of students in GSA and GSB is 231 and 290, respectively. Although both the head teachers perceived that they were effectively fulfilling their instructional responsibilities, their practices and the opinions of teachers did not endorse the claims of the two administrators. The ensuing paragraphs encompass the head teachers' contributions towards the supervisory processes and in-school professional development activities.

\subsection{Supervisory Processes}

The administrators' guidance and evaluation of their teachers' instructional tasks determine the effectiveness of a school (Lassibille \& Tan, 2003). The head teacher of GSA believed that his supervisory duties are limited to the following activities: timely opening of school, monitoring the presence of teachers and administrative staff, and identifying substitute teachers. On each day, the head teacher of GSA makes two visits in his school; he stated the following about these visits:

First of all, I check the availability of teachers. Then, I check whether the teacher gives lectures or writes on the blackboard... If a teacher writes a wrong word on the blackboard, I will privately tell him about his mistake. If everything is okay during the class visit, I will leave the room with an appreciation of the class teacher.

While accompanying the head teacher during these visits, I noticed that instead of providing feedback about the teaching methodologies, the head teacher would deliver lectures on moral values; he would not talk about pedagogy, and he never asked whether or not the teachers develop lesson plans. The head teacher of GSA reiterated on many occasion that during the next 18 months he would be retiring from his services; therefore, he did not want to put forth any extra effort. Additionally, because he perceived teaching as the responsibility of teachers, he did not want to interfere in their jobs. Teachers believed that his expected retirement, in addition to other issues, made their head teacher less mindful about improving the instructional quality of his school.

Additionally, the teachers of GSA pointed out that neither prolonged teaching experiences nor numerous training opportunities helped their head teacher develop an in-depth understanding about such instructional practices as providing feedback to teachers, visiting classes, observing teachers, etc. One of the teachers stated, "Supervision is an important responsibility of the headmaster, but our headmaster does not understand the meaning of supervision... he only defines supervision to keeping eyes on availability of teachers in school.” 
Another teacher reflected on the supervisory behavior of his head teacher:

On two occasions I even went to his office to convince him to come out of his office; otherwise, he was not ready to do those visits. He needs to visit the classes because that is the only way he will begin to understand what is going on in the classes. He needs to visit classes to learn about the performance of his teachers. Unfortunately, I am not successful in my endeavors because I could not convince my headmaster.

Teachers pointed out that the academic qualification of their head teacher, which was in the subject of Persian, did not help him to become an instruction-oriented leader. One teacher explained this situation as follows:

I do not blame the headmaster for his inefficiency because he did not receive any professional development opportunities related to his job. Because he was also a teacher like us, he has the same qualifications that we have and the same expertise, but he was waiting for his turn to advance. One day his turn came, and he became a headmaster.

I observed that the head teacher had maintained a very cordial and friendly relationship with his staff; teachers would frequently visit his office to discuss all the issues and topics (except academic matters) and to watch the cable television installed in his office, but such a relationship made limited contributions towards the instructional development of the school. One teacher stated the following:

I come to school in the morning and shake hands with my headmaster and this is a routine. I don't think this is a proper way of communication. The real communication will happen when the headmaster visits the classes, questions the teachers, and interacts with the students and listens to their complaints.

Additionally, I noticed that the school had no formal system of assessment through monthly tests and quizzes. One of the teachers said the following:

One day, I suggested to the head teacher that he should ask the teachers to give class tests and quizzes. I told him that in this way we would better prepare our students for the internal and Board examinations. Instead of appreciating my suggestion, he became angry and told me that I should not create problems for him. Since then, I have never discussed this topic with my headmaster.

Although it is mandatory for the head teachers in government schools to teach some classes, the head teacher of GSA did not engage in such activities. However, he claimed that he participated in classroom teaching on a need basis, "I pay great attention to the education in this institution... if a teacher is absent, I either arrange for a substitute teacher or teach the class myself". One of the teachers commented on the non-involvement of the head teacher in teaching, "The school offers Arabic subjects to its students, but the school does not have an Arabic teacher. Despite the fact that Mr. Salman (head teacher) is a trained Arabic teacher, he does not teach an Arabic class”. During the research period, I did not notice a single occasion where the head teacher served as a substitute teacher.

Although the retirement of the head teacher of GSB was also expected in two years, the head teacher of GSB was more proactive in the academic development of his school than his counterpart. The head teacher of GSB addressed the lack of a required teaching staff by teaching three regular classes and occasional substitute classes. Since assuming the charge of headship, he initiated numerous academic measures that enabled the teachers to develop a positive opinion of him. For instance, the school has a small library that does not accommodate a large number of students; the head teacher initiated construction work to add an open space in the library for a larger number of students. Similarly, the head teacher and his staff significantly reduced student absenteeism. The head teacher stated that besides teaching regular and substitute classes, he carries out multiple tasks that contribute to the overall academic environment of his school, such as providing instructional resources, arranging co-curricular activities, etc. He explained his supervisory role as follows:

Although I visit classes and monitor the teaching activities, these visits are not frequent. I only visit classes when I receive complaints from students about the teaching methodologies of a particular teacher or a teacher invites me for guidance or wants my help with lessons... I have this belief that if the teaching processes is progressing smoothly, I should not disturb the teachers by making surprise visits.

When I asked the head teacher about what particular aspect of teaching he notices while making occasional supervisions and visits, he replied that he checks the lesson plans as well as the teaching methodologies: 
Each class maintains a class diary where the teachers of different subjects provide the detail of their daily lesson as well as those activities that relate to the subject. I check the class diary of different teachers and subjects on a regular basis. In this way I develop a sense about the lesson planning practices of my teachers and their teaching practices... later on I privately provide the teacher with feedback.

A review of the said class diary showed that teachers provided only partial information about the lessons they taught and the activities they conducted. For instance, the biology teacher only wrote "developing charts" instead of providing the details of the topic and related activities. Likewise, the English teacher only wrote the name of the topic "mode of transportation". The teachers did not confirm the claim of their head teacher about the lesson planning practices of teachers. They mentioned that the teachers did not develop the lesson plans and the head teacher did not ask them about these activities.

Although the teachers of GSB were appreciative of the some of the academic contributions of their head teacher, they were not explicit or enthusiastic while commenting on the supervisory role of their head teacher. One of the teachers commented as follows on the supervisory role of his head master:

No doubt he is nice and hardworking; he properly addresses the issue of shortage of teachers, but he is not an ideal head teacher. I got a chance to attend a training session on school leadership and management that helped me to develop a sense of educational leadership. Additionally, I have extended teaching experience, and I understand what defines supervision. Unfortunately, our head teacher is not proactive in the supervisory field. Even two years since assuming the charge of headship, he has not once visited my room to monitor my teaching methodologies.

Another teacher commented about the limited role of his head teacher in the process of supervision: "He should come to our class and monitor our teaching practices, but he avoids carrying out this task. He might have this feeling that teachers are not well-prepared and his surprise visit could make them uncomfortable... in fact, our head teacher is a nice gentleman”. Teachers also commented that the administrative nature of his job, in addition to his teaching responsibilities (both regular and substitute), prevent him from monitoring and observing classes. I observed the truth of this statement; after teaching classes, the head teacher spent his remaining time on taking care of multiple administrative jobs such as addressing the disciplinary problems of students, dealing with the issues of new admission, replying to the queries of central office, etc. The head teacher also admitted that his preoccupation with administrative tasks prevent him from carrying out three annual formative assessments that determine the future promotions of teachers. A review of the formative assessment register supported the words of the head teacher because for the last two years he had carried out the formative assessment of only one teacher of his school. Similarly, in his communication with his staff, the head teacher concentrated on administrative tasks, not academic matters.

Both the head teacher and teachers agreed that the organizational culture is not supportive for the head teacher's supervisory role. One of the teachers attributed the limited supervisory role of the head teacher to the lack of awareness about the instructional responsibilities of school administrators in Pakistani schools:

I blame the system if the head teacher does not participate in supervision... the reason for this situation is that neither the head teachers nor the teachers understand that supervision is the fundamental responsibility of the head teacher. I have noticed teachers get offended when the head teacher attempts to monitor the teaching methodology of a particular teacher as the teacher considers this act of head teachers as spying or keeping an eye on their activities... the head teacher, who recognizes this situation, is not motivated to supervise because he does not want to annoy his staff.

Another teacher stated that if the students complain about the teaching methodologies of their teachers, the head teacher would tell the students that the school has those teachers and the students need to accept them. One teacher added:

In fact, the head teacher is unable to ask the teachers because he knows the system has many loopholes... you have noticed that the pages of the formative assessment register were blank, despite the fact that the head teacher needs to carry out these assessments in a candid way. Our head teacher is just a controller of three things: scheduling classes, arranging substitute teachers, and addressing administrative issues.

Teachers agreed that the limited supervisory practices of their head teacher is not an exception; instead, al- 
most all the public school head teachers are less familiar with this aspect of their position. One of the teachers stated the following:

I have been in the teaching profession for the last eleven years; during these eleven years, I have not seen a single head teacher [in the public school system] who participated in supervisory activities. Head teachers know these supervisory activities are fruitless because neither the teachers nor the system changes. The only punishment for underperforming teacher is posting to a new school.

\subsection{In-School Capacity Building Opportunities}

One of the fundamental tasks of school principals is to develop an environment where the education of individuals and organizations could take place simultaneously through prioritizing the learning process and inspiring others to embrace learning opportunities (Payne \& Wolfson, 2000). However, the two head teachers had different interpretations concerning their limited efforts regarding in-school capacity building opportunities. The two head teachers neither introduced a culture that facilitated the in-school learning opportunities nor devised a mechanism to determine the professional development needs of their teachers. When asked the reason for not initiating such activities at the school level, the head teacher of GSA replied, "It is not my responsibility to develop plans and strategies for the training of my teachers; instead, the government or the central directorate of education has the responsibility to first determine the needs and then offer the appropriate training”.

The teachers reinforced the head teacher's (of GSA) perceptions about in-school professional development opportunities. Not only did they question the role of their head teacher in implementing these opportunities, but they also asserted that their head teacher discouraged them from initiating these activities. One of the teachers stated the following, "Our head teacher prevents us from participating in training opportunities by arguing that imparting training within school is not the job of teachers; instead, an external resource person should arrange and provide a specialized training”. Another teacher explained the discouraging behavior of his head teacher as follows: "I once suggested to the head teacher that he should plan activities within the school that use the skills and expertise of teachers. He responded that such activities are not possible in the school. Also, he does not trust the expertise and skills of teachers, despite the fact that we have good science and math teachers in our school". A third teacher of GSA reflected on the negative reaction of the head teacher to a team teaching experience involving a mathematics lesson:

One day I was sitting in one of the classes and observing a mathematics lesson of one of my colleagues. The intentions of my observations were to guide my colleague regarding his methodologies and to learn some of his expertise. Team teaching is a good method; we were both helping each other. He was delivering his lecture, and I was a passive observer. Because it was winter and the class was held in an open space, our head teacher was observing the process. He made no objections on the first two days, but on the third day he asked me to stop observing the class. I told him that I was not disturbing the class, but the headmaster did not agree with me. Instead, he said two teachers should not sit in one class at the same time.

One of the teachers of GSA argued that his head teacher lacks the qualities of a good role model because he fails to offer an environment where the learning of both the teachers and students could take place simultaneously:

The headmaster can become a role model if he engages in educational-related activities. For instance, he can develop a model lesson and deliver it before the teachers... If an administrator is efficient, the staff will be efficient as well. You have noticed that the communication between the head teacher and the school staff is only confined to discussing administrative matters.

As mentioned earlier, the nature of the relationship between the head teacher of GSA and his staff was very cordial and friendly; however, it was also noticed that such a friendly relationship had a limited influence on the overall academic climate of the school.

The GSA had a Teachers Resource Center (TRC) that was equipped with projectors, computers, and a small volume of books. The TRC was supposed to be utilized for the capacity building of the teachers. However, teachers reported that their head teacher did not allow them to use the TRC, another indication of their head teacher's limited interest in enhancing the learning of the teachers. One of the teachers commented on the head teacher's reluctance of the usage of the TRC: 
Primarily the TRC was established for the sake of the teachers' capacity building, but the head teacher prevents the teachers from using the room. Our head teacher does not trust us; since he is retiring from his services during the next few months, he is afraid that someone might steal the equipment of TRC and he will be in trouble. Therefore, he produces different excuses, and the purpose of these excuses is to simply discourage us.

The head teacher stated the following concerning the non-availability of the TRC: "The TRC is the property of the College of Education (situated in the neighborhood), which uses this room for the training purposes of its students. I take special care of this room because it houses expensive equipment”. The teachers agreed that the facility was the property of GSA. During the course of this research, I got a chance to visit the TRC and noticed layers of dust on the computers, digital projectors, and other equipment. An electric vacuum cleaner, which was provided to maintain the cleanliness of the TRC, stood in a corner and was covered with dust.

The teachers of GSA also pointed out that there is a general perception among the teachers and head teachers of government schools that only those activities held out of school and extending monetary benefits to the trainees are considered as capacity building opportunities. One of the teachers mentioned the following when identifying gaps in government-led initiatives: "The educators in government schools enhance their qualifications for the sake of monetary gains and promotions, not to update their knowledge”. Teachers also lamented that their head teacher neither facilitated the in-school learning nor put into place the mechanism to determine the needs of teacher for a particular training arranged by the central directorate of education. In most of the cases, the likes and dislikes of head teachers play an important role in deciding the nature of the training; sometimes this result in having the wrong people for the wrong training. One teacher stated, "I am a social science teacher, but I was asked to attend computer training. Although I attended the computer training, I never used these competencies because they are not compatible with my subject”.

The practices of the head teacher of GSB were not different from those of the head teacher of GSA in terms of arranging in-school professional development activities for teachers. Both the head teacher and teachers had either little or no sense about this aspect of headship. The head teacher of GSB agreed that teachers need sustained professional development because of the changing nature of education, but he had this notion that schools are not the ideal places for these activities: "No, we cannot arrange these activities at school level because we have classes and we have children in-school... the normal processes of students learning will suffer and we cannot close school for such activities... additionally, we don't have enough resources for these activities”. Although he occasionally provide guidance to his teachers about the best teaching practices, he admitted that he restricts his guidance to methodology because his competencies are confined to selected subjects. Teachers believed that since they have protracted teaching experience with such degrees as Primary Teaching Certificate, B.Ed, etc, they do not need further training. One of the teachers explained, "Only novice teachers need training because they have just started this profession... we neither need these in-school trainings nor do we expect the head teacher to arrange such activities for us”. Both the head teacher and teachers agreed that discussing educational issues during the recess or tea break is enough for updating the knowledge of educators. In this regard, one of the teachers elaborated the role of his head teacher by stating, "Our head teacher calls meetings where we discuss multiple academic and non-academic issues, such as dealing with the lack of teachers, arranging substitute teachers, developing timetables, and addressing disciplinary issues. In this way, teachers enhance their understanding about the academic matters of school”. However, I did not notice a single occasion in which the head teacher and teachers discussed the academic issues of their school during the recess time; instead, they confined their discussions to either administrative matters or personal issues. Additionally, teachers admitted that meetings are called on a need basis, not to discuss instructional issues.

However, the head teacher was critical of his teachers for not taking interest in activities that could enhance their knowledge. He reflected on his only effort in this regard:

I attended a training session where I learned how to teach the English subject... I came back and shared what I had learned with my teachers, expecting they would benefit from my experiences... the teachers neither welcomed my input not did they integrate what I shared with them into their practices... I have no idea whether they did not understand what I was sharing with them or they were not interested.

The head teacher asserted that non-readiness of his teaching staff was another reason of his limited involvement in in-school learning initiatives. He added that there are very few teachers who take their jobs seriously 
because they see the "teaching profession as just a source of income". The head teacher also blamed the system for not developing a mechanism that could motivate the teacher to participate in such kinds of learning practices:

There are teachers in our system who does not want to change, even if I provide them with some coaching, and the education of children really suffers because of these kinds of teachers. I cannot fire these teachers; the only punishment is to transfer them to another school... when I see these things, I prefer not to participate in these activities.

Some of the teachers agreed with the assessment of their head teacher regarding their limited interest in in-school professional development programs. One of the teachers stated the following:

We are neither motivated nor interested in these activities because it does not make any difference whether or not we attend these sessions. In fact, in government schools we don't have the mechanism or framework that could hold accountable both the teachers and head teachers for such activities...since the accountability is missing, we do not care about these initiatives. Additionally, we have little interest in these activities because they are not linked to our promotions or monetary benefits.

One of the teachers reflected on his experience of attending an out-of-school capacity building opportunity:

My head teacher sent me to attend a two-week long foreign funded training in another city that was focusing on new methods of teaching science subjects. The session was very enriching in terms of learning new methodologies and approaches for teaching science subjects. However, when I returned from the training, I noticed that none of my colleagues showed any interest in what I had learned. Their low level of enthusiasm led me to speak no further about my training.

He added that during the training, trainers had encouraged the participants to conduct sessions for other science teachers once they returned to their respective regions, "but I did not conduct any session and no one asked me because there is no mechanism of follow-up in the government system”. Despite their lack of interest in training, the teachers did appreciate the merit-oriented behavior of their head teacher. They emphasized that he always recommended the right people for the right training [arranged by central office], a practice not common in government schools.

\section{Discussion and Analysis}

Today, school leaders in the developed countries are dealing with the implications of advances of science and technology on the daily business of schools (Mulford, 2008). However, school leaders in developing countries including Pakistan are still wrestling with numerous organizational processes that minimize their efforts to address the issues related to educational quality. In fact, there is a lack of recognition of school leaders as significant players in the provision of quality education in Pakistan (Oduro, Dachi, Fertig, \& Rarieya, 2007). After examining the instructional practices of two head teachers, the study agrees with the researchers who noted that within schools the performance of principals is largely influenced by the behavior of staff and numerous organizational and structural processes (Bush \& Glover, 2003; Hallinger \& Murphy, 1985). Unlike the other public schools of Pakistan, which face a plethora of issues, such as lack of adequate resources and overcrowded classrooms, the two schools where the study was conducted had very acceptable student-teacher ratios and had all the resources required for the teaching and learning processes. Despite these advantages and the protracted teaching experience of the two head teachers, the contribution of the two head teachers towards the instructional development of their schools was questionable. It seemed that the disengagement of the two head teachers from the supervision and promotion of teachers' learning was the result of a host of factors, such as the absence of proper orientation, a vague understanding about the responsibilities of head teachers, a low level of motivation of head teachers, and an in-effective accountability process.

The practices of the two head teachers suggest that head teachers in Pakistani public schools are neither accountable nor responsible for engaging in instruction-related tasks; instead, teaching and learning are exclusively the domains of teachers. Although some teachers in both the schools felt that their head teachers must be engaged in in-classroom activities, it seemed that that the majority of the teachers and the two head teachers were naïve about the instructional dimensions of head teachers. The head teachers attributed their choice to not participate in classroom (supervision) and in-school (professional development) activities to the availability of ex- 
perienced teachers; this raises questions about the orientation and development of head teachers in the Pakistani educational context where the length of teaching experience rather than the acquisition of certain instructional skills determines the suitability of individuals for the position of headship. Although both developed and developing countries have recognized that the provision of job-related training for head teachers is essential for maintaining the instructional quality of education (Bush, 2008; Grauwe, 2004; Herriot et al., 2002; Bajunid, 2000), Pakistani school administrators, due to their lack of job-related training, have only a very vague understanding of their jobs; the focus on administrative duties by the two head teachers in this study reinforces this conclusion. Both the head teachers acknowledged that their protracted teaching experience enabled them to understand the roles and responsibilities of headship. One of the head teachers stated, "I don't need special training because I know what I have to do as a head teacher... I have been watching my predecessors for many years...I am doing whatever they did as headmaster”. Bush (2008) has equated the appointment of non-trained principals for schools to gambling, explaining that it is inappropriate to gamble when the losers are students. Under these circumstances, it might be helpful to first redefine the position of Pakistani headship and to then develop coherent policies that could generate school leaders because, as the literature suggests, leadership has a strong association with change.

It has been acknowledged that in Pakistan neither the regular teachers preparation programs nor the occasional professional development opportunities provided to head teachers help these head teachers to develop a sound understanding about the concepts, such as leadership and management, monitoring and evaluation, and school improvement programs (Khan, 2004; Memon, 2000; Kandasamay \& Blaton, 2004). Therefore, a two-pronged strategy needs to be adopted in order to address the gaps related to leadership preparation programs in Pakistan. First, intensive empirical research is required to determine the roles, challenges, and professional development needs of school administrators because "given the importance of leadership in the current education policy environment around the world, better knowledge about effective leadership and its development should be a high priority” (Huber \& Pashiardis, 2008: p. 296). In this regard, Bush (2008) stated the following, "Because preparation for new principals is limited, there is inevitably little literature on the nature and quality of provision” (p. 40). The findings of the said research can determine the adequate strategies, appropriate curricula and required competencies for the leadership development programs. While addressing the aforementioned variables, emphasis should be given to the instructional model of leadership. Although the said model has been developed in the context of the developed world, numerous ingredients of this model can be applicable in other contexts such as supervision, curriculum enrichment, and in-school professional development.

Second, the selection and induction of head teachers need to be redefined. Since a significant number of Pakistani higher educational institutions are currently offering programs in school leadership and management, these programs should be required for the position of headship. When appointing a school leader, emphasis should be given to whether or not the individual has the motivation (Peterson, 1987) or personal disposition (Greenfield, 1987) to carry out the job of principalship. As the present study shows, an expected retirement made the two principals less motivated to strive for change. Due to the changing nature of education and school leadership, several developing countries have revised their selection processes. For example, in Malaysia and Bhutan, the selection of new principals is not only based on certain period of teaching experience but also on the individuals' personal characteristics, general skills, and capacity for growth (ANTRIEP, 2000). In Malaysia, school heads are required to attend three weeks of training and participate in short courses that are oriented to instructional leadership (Bajunid, 2000). These trainings and courses integrate such themes as organizational development, pedagogical development, and politics and economics of education.

As mentioned earlier, both the head teachers and a significant number of teachers in the two schools had a very limited understanding of the instructional role of school principal. These individuals explicitly stated that providing training in school is not the job of head teachers; instead, the teachers assumed that they had enough training and that the central office, not head teacher, had the responsibility to provide the training. "With no clear definition of who they are and what they are supposed to do” (Warwick \& Reimers, 1995: p.101), both of the head teachers engaged in tasks that had no direct link to instruction and pedagogy, despite the fact they had sufficient time to focus on such activities. In addition, the two head teachers showed confidence when they explained they understood their job responsibilities because they had observed how their predecessors performed. It seemed that an absence of a clear job description made the two principal less familiar with the instructional role of headship. Generally, neither the school principals nor the teachers in Pakistani public schools receive a job description at the time of their appointment. In the context of developing countries, Bush (2008), while ela- 
borating on the different strategies of developing school leaders, suggested, "Developing a clear job description, and linking candidates' experiences to these requirements, provides a useful starting point”' (p. 106). Therefore, it is essential that both the Pakistani head teachers and teachers should receive job descriptions that clarify their responsibilities. The job descriptions should emphasize that school leaders are responsible for improving the teaching of their staff and the learning of their students. As instruction-oriented leaders, they should know what comes under the umbrella of the administrative (decision-making processes, delegation, goal orientation, etc.), educational (supervision, guidance, development, etc.), and social (motivation, personal care, trust, etc.) functions of principals (Dalin, 1998). Research suggests that the provision of job description serves two important purposes: 1) it helps the employees to understand the responsibilities, functions, and requirements of a particular job and 2) it helps in the evaluation of the performance of employees (Palumbo, 2011). A lack of defined roles makes it very difficult to clearly assess the role of head teachers in Pakistani schools (Khan, 2004: p. 8). Therefore, it could be assumed that the absence of defined roles and the lack of an appraisal mechanism led the two head teachers to become less involved in the supervisory and instructional processes.

The head teachers and teachers agreed that because the system neither explicitly asks the principals to get involved in in-class room practices nor holds them accountable for these tasks, head teachers are less motivated to engage in supervisory activities. Although one of the school heads had maintained a daily classroom diary and register for assessing the teaching practices of his teachers, the effectiveness of the two registers was questionable; the officials of the education department neither properly maintained nor monitored the registers. Under these circumstances, it is essential to 1) determine the role of Pakistani principals as leaders capable of understanding their responsibility as major contributors of teaching and learning and 2) to devise a mechanism that could hold the principals accountable while using teaching and learning as the primary parameters of the evaluation of head teachers. Currently, there is no such tool that could be used to measure the contribution/performance of schools heads in Pakistani schools. Researchers have favored the integration of accountability and control for improving the standards of education in schools (Peterson, 1987; McEwen, Fagan, Earl, Hodgkinson, \& Maheu, 1995) because accountability leads and motivates individuals to use their best energies and resources to achieve the organizational goals. In the context of Pakistani schools, it has been found that the lack of resources is not an issue that contributes to the low instructional quality of public schools; this study notes that the Teacher Resource Centre (TRC) was not available for the teachers and a foreign-funded computer laboratory was not accessible for the students (in one of the schools). Instead, it seems that the people who control these resources are either unable to take advantage of them or make no effort to use them since the system does not hold their accountable for their decisions.

Today, whether schools are located in developed or developing countries, the emphasis is on learning outcomes and quality of education (Bruns, Filmer, \& Patrinose, 2011; Fidler, 1997) and the emphasis on quality has made the school leaders more accountable (Olayiwola, 2012). Therefore, school administrators and teachers in Pakistan need a robust accountability mechanism. This mechanism should link the continuity of jobs of administrators and teachers to the performance of these educators. Additionally, the accountability process should include both the parents and communities. Such participation has remained a successful approach for evaluating the performance of educators and administrators in a number of developed and developing countries (Bruns, Filmer, \& Patrinose, 2011; Bush, 2008). Although School Management Committees (SMC) and Parent Teachers Councils are part of Pakistani public schools, in most cases their role and contributions are symbolic and limited in terms of monitoring the quality of education or evaluating the educators. These entities need to be recognized as an important element of the accountability procedures of school administrators and teachers.

\section{Conclusion and Recommendations}

Unlike in the past, when the quantitative expansion of education is the primary focus of developing countries, the current focus is more on the qualitative improvement of instruction and learning. This change reinforces the need for the redefinition of the roles of school leaders in developing countries including Pakistan. Based on the findings of this study, it is recommended that the position of school heads should be redefined by making it more instruction oriented. It is expected that school leaders should acquire the essential knowledge and skills that can be instrumental in addressing the teaching and learning processes of schools. Introducing a new organizational culture is a first step in this direction that can address such concepts as the re-conceptualization of school heads, the provision of proper orientation/training, and a robust accountability mechanism. 


\section{References}

ANTRIEP (2000). Improving School Efficiency: The Asian Experience. Paris: International Institute of Educational Planning, UNESCO.

Bajunid, I. A. (2000). Educational Management and Leadership in Malaysia: The Training and Professional Development of School Principals. Asia-Pacific Journal of Teacher Education and Development, 3, 49-75.

Blasé, J. (1987). Dimensions of Effective School Leadership: The Teacher's Perspective. American Educational Research Journal, 24, 589-610. http://dx.doi.org/10.3102/00028312024004589

Blase, J., \& Blase, J. (1999). Principals’ Instructional Leadership and Teacher Development. Educational Administration Quarterly, 35, 349-378. http://dx.doi.org/10.1177/0013161X99353003

Bruns, B., Filmer, D., \& Patrinos, H. A. (2011). Making Schools Work: New Evidence of Accountability Reforms. Washington DC: The World Bank. http://dx.doi.org/10.1596/978-0-8213-8679-8

Bush, T. \& Glover, D. (2003) School Leadership: Concepts and Evidence. National College for School Leadership, Nottingham.

Bush, T. (2005). Preparation for School Leadership in the 21st Century: International Perspectives. Paper read at First Head Research Conference, Oslo: University of Lincoln.

Bush, T. (2009). Leadership Development and School Improvement: Contemporary Issues in Leadership Development. Education Review, 61, 375-389. http://dx.doi.org/10.1080/00131910903403956

Bush, T. (2008). Leadership and Management Development in Education. Los Angeles: Sage Publications.

Dalin, P. (1998). Leadership and Management Theory (2nd ed.). London: Continuum International Publisher.

Douglas, A. (1988). Administration in Less Developed Countries: Consideration for Educators. The Journal of Educational Administration, 26, 367-381. http://dx.doi.org/10.1108/eb009957

Fidler, B. (1997). School Leadership: Some Key Ideas. School Leadership and Management, 17, 23-37. http://dx.doi.org/10.1080/13632439770140

Fink, E., \& Resnick, L. B. (1999). Developing Principals as Instructional Leaders. Pittsburgh, PA: Learning Research and Developing Centre, University of Pittsburgh.

Fuller, B. (1987). What School Factors Raise Achievement in the Third World? Review of Educational Research, 57, 255292. http://dx.doi.org/10.3102/00346543057003255

Grauwe, de. A. (2004). Improving Quality by Reforming School Management in Asia. Newsletter: International Institute for Educational Planning.

Greenfield, W. (1987). Moral Imagination and Interpersonal Competence: Antecedents to Instructional Leadership. In W. Greenfield (Ed.), Instructional Leadership: Concepts, Issues, and Controversies. Boston, MA: Allyn and Bacon, Inc.

Hallinger, P., \& Murphy, J. (1985). Assessing the Instructional Management Behavior of Principals. The Elementary School Journal, 86, 217-247. http://dx.doi.org/10.1086/461445

Hallinger, P., \& Murphy, J. (1987). Instructional Leadership in the School Context. In W. Greenfield (Ed.), Instructional Leadership: Concepts, Issues and Controversies. Boston, MA: Allyn and Bacon, Inc.

Harber, C., \& Davies, L. (1997). School Management and Effectiveness in Developing Countries. The Post Bureaucratic School. London: Cassel.

Herriot, A., Crossley, M., Juma, M., Waudo, J., Mwirotsi, M., \& Kamau, A. (2002). The Development and Operation of Head Teacher Support Groups in Kenya. A Mechanism to Create Pockets of Excellence, Improve the Provision of Quality Education and Target Positive Changes in the Community. International Journal of Educational Development, 22, 509526. http://dx.doi.org/10.1016/S0738-0593(00)00040-7

Hoodbhoy, P. (Ed.) (1998). Education and State, Fifty Years of Pakistan. Oxford: Oxford University Press.

Huber, S. G., \& Pashiardis, P. (2008). The Recruitment and Selection of School Leaders. In J. Lumby, G. Crow, \& P. Pashiardis (Eds.), International Handbook on the Preparation and Development of School Leaders (pp. 176-202). New York: Routledge Taylor and Francis.

Jenkins, B. (2009a). What It Takes to Be an Instructional Leader. National Association of Elementary School Principals.

Jenkins, B. (2009b). What It Takes to Be Instructional Leader. www.elead.org/resources/resources.asp?ResourceID=14

Kandasamay, M., \& Blaton, L. (2004). School Principals: Core Actors in Educational Improvement, an Analysis of Seven Asian Countries School. Paris: International Institute for Educational Planning.

Khaki, J. A. (2005). Exploring the Beliefs and Behaviors of Effective Head Teachers in the Government and Non-Government 
Schools in Pakistan. PhD Dissertation, Retrieved from ProQuest Database, AAT.NRO 2738.

Khan, A. (2010). A Case Study Exploring Perceived Professional Development Needs for Secondary School Administrators in Pakistan. Unpublished PhD Dissertation, Pittsburgh, PA: Administrative and Policy Studies, School of Education, University of Pittsburgh.

Khan, A. (2012). Instructional Management of a Private and a Government Secondary School Principal in Northern Pakistan. International Journal of Educational Development, 32, 120-131. http://dx.doi.org/10.1016/j.ijedudev.2010.12.003

Khan, H. (2004). Better School Management in the Islamic Republic of Pakistan: The Role of Head Teacher. In M. Kandasamay, \& L. Blaton (Eds.), School Principals: Core Actors in Educational Improvement, an Analysis of Seven Asian Countries (pp.59-113). Paris: International Institute for Educational Planning.

Kizilbash, H. H. (1998). Teaching Teacher to Teach. In P. Hoodbhoy (Ed.), Education and State, Fifty Years of Pakistan (pp. 102-135). Karachi: Oxford University Press.

Krug, S. E. (1992). Instructional Leadership: A Constructivist Perspective. Educational Administration Quarterly, 28, 430443. http://dx.doi.org/10.1177/0013161X92028003012

Lassibille, G., \& Tan, J. P. (2003). Student Learning in Public and Private Primary Schools in Madagascar. Economic Development and Cultural Change, 51, 699-717. http://dx.doi.org/10.1086/374678

McEwan, E. K. (2003). 7 Steps to Effective Instructional Leadership (2nd ed.). Thousand Oaks, CA: A Sage Publications. http://dx.doi.org/10.4135/9781483328775

McEwen, N., Fagan, L. P., Earl, L., Hodgkinson, D., \& Maheau, R. (1995). Reflections and Clarifications. Canadian Journal of Education, 20, 99-107. http://dx.doi.org/10.2307/1495058

Memon, M. (2000). Re-Conceptualizing the Role of Head Teachers as Pedagogical Leaders in Pakistan: Implication for Policy Reforms. Education, 3, 6-10.

Memon, M., \& Bana, Z. (2005). Pedagogical Leadership in Pakistan: Two Head Teachers from the Northern Areas. In: J. Retallick, \& I. Farah (Eds.), Transforming Schools in Pakistan. Towards the Learning Community. Karachi: Oxford University Press.

Memon, M., Ali, R. N., Simkins, T., \& Garrett, V. (2000). Understanding the Head Teacher’s Role in Pakistan: A Case Study. International Studies in Educational Administration, 28, 48-56.

Ministry of Education (2009). National Educational Policy Draft 2009. Government of Pakistan.

Mohammad, R. F., \& Jones, B. H. (2008). Working as Partners for Class Room Reforms. International Journal of Educational Development, 28, 534-545. http://dx.doi.org/10.1016/j.ijedudev.2008.01.006

Mulford, B. (2008). The Leadership Challenge: Improving Learning in Schools. Australian Council for Educational Research.

Oduro, G., Dachi, H., Fertig, M., \& Rarieya, J. (2007). Examining Educational Leadership and Quality in Developing Countries. EdQual, 9.

Ogawa, R. T., \& Malen, B. (1991). Towards Rigor in Review of Multivocal Literatures. Applying the Exploratory Case Study Method. Review of Educational Research, 61, 265-286. http://dx.doi.org/10.3102/00346543061003265

Olayiwola, S. (2012). Leadership for Quality and Accountability in Education. School Leadership and Management, 32, 397-399. http://dx.doi.org/10.1080/13632434.2012.708331

Oplatka, I. (2004). The Principals in Developing Countries: Context, Characteristics and Reality. Comparative Education, 40, 428-448. http://dx.doi.org/10.1080/0305006042000274872

Palumbo, R. (2011). The Importance of a Job Description and Its Impact on Employee Evaluations. http://voices.yahoo.com/the-importance-job-description-its-impact7690168.html

Pansiri, N. O. (2008). Instructional Leadership for Quality Learning. An Assessment of the Impact of the Primary School Management Development Project in Botswana. Educational Management Administration and Leadership, 36, 471-494. http://dx.doi.org/10.1177/1741143208095789

Payne, D., \& Wolfson, T. (2000). Teacher Professional Development-The Principal’s Critical Role. NASSP Bulletin, 84, 13-21. http://dx.doi.org/10.1177/019263650008461803

Peterson, K. D. (1987). Administrative Control and Instructional Leadership. In W. Greenfield (Ed.), Instructional Leadership: Concepts, Issues, and Controversies. Boston, MA: Allyn and Bacon, Inc.

Plank, D. N. (1987). School Administration and School Reforms in Botswana. International Journal of Educational Development, 7, 119-126. http://dx.doi.org/10.1016/0738-0593(87)90044-7

Rizvi, M. (2008). The Role of School Principals in Enhancing Teacher Professionalism: Lessons from Pakistan. Educational Management Administration and Leadership, 36, 85-100. http://dx.doi.org/10.1177/1741143207084062 
Simkin, T., Garret, V., Memon, M., \& Ali, R. N. (1998). The Role Perception of Government and Non-Government Head Teachers in Pakistan. Educational Management and Administration, 26, 131-146. http://dx.doi.org/10.1177/0263211X98262003

Stake, E. R. (1995). The Art of Case Study Research. Thousand Oaks, CA: Sage Publications.

Stark, S., \& Torrance, H. (2005). Case Study. In B. Somekh, \& C. Lewin (Eds.), Research Methods in Social Science. Thousand Oaks, CA: Sage Publications.

UNESCO (2003). Quality of Primary Education in Pakistan. Islamabad: Ministry of Education. http://unpan1.un.org/intradoc/groups/public/documents/APCITY/UNPAN020045.pdf

USAID (2006). Situation Analysis of Teacher Education in Pakistan: Towards a Strategic Framework for Teacher Education and Professional Development.

Wallace Foundation (2012). The School Principal as Leader: Guiding Schools to Better Teaching and Learning. http://www.wallacefoundation.org/knowledge-center/school-leadership/effective-principal-leadership/Documents/The-Sch ool-Principal-as-Leader-Guiding-Schools-to-Better-Teaching-and-Learning.pdf

Warwick, D. P., \& Reimers, F. (1995). Hope or Despair: Learning in Pakistan's Primary Schools. Westport, CT: Praeger Publisher.

Waters, T., \& Marzano, R. (2006). School District Leadership That Works: The Effect of Superintendent Leadership on Student Achievement. Working Paper, Aurora, CO: Mid-Continent Research for Education and Learning (McREL). 